\title{
Power flow variation based on extreme learning machine algorithm in power system
}

\author{
Labed Imen, Labed Djamel \\ Laboratory of Electrical Engineering, Department Of Electrical Engineering, University of Constantine 1, Algeria
}

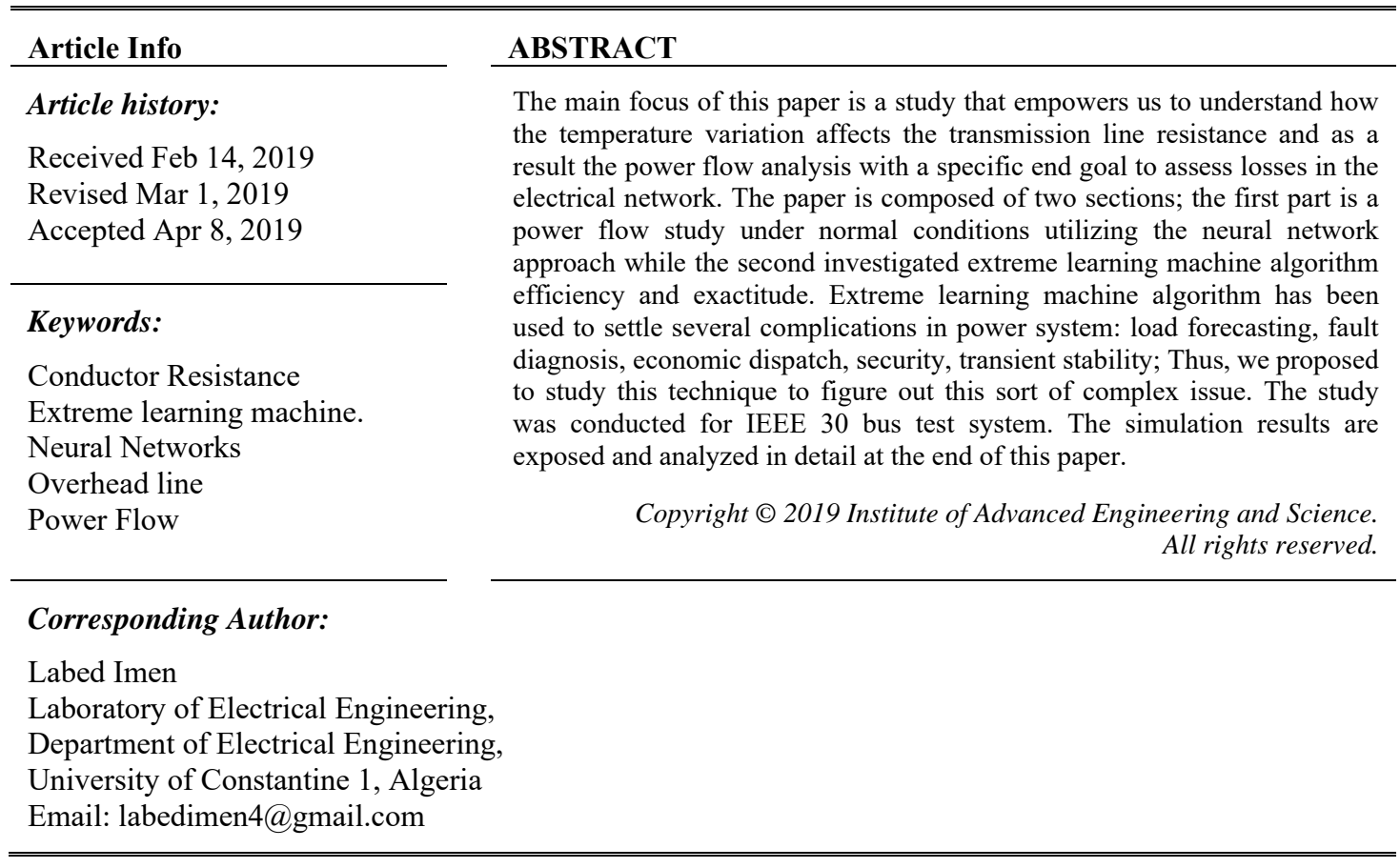

\section{INTRODUCTION}

Electric power systems are real-time energy delivery systems. Real-time means that power is generated transported and supplied the moment we turn on the light switch [1]. Electric power systems are not storage systems like water and gas systems. Instead, generators produce the energy as the demand calls for it $[2,3]$.

The huge amount of power generated in a power station (hundreds of $\mathrm{MW}$ ) is to be transported over a long distance (hundreds of kilometers) to load centers to cater power to consumers with the help of highvoltage transmission line in order to reduce transportation losses. Transmission and distribution losses reach a rage of $4 \%$ to $5 \%$ of the total consumption. The higher-voltage transmission lines require larger structures with longer insulator strings in order to have greater air gaps and needed insulation.

Conductor material (all wires), type, size, and current rating are key factors in determining the power handling capability of transmission lines. A conductor heats up when current flows through it due to its resistance, conductors tend to increase their resistance with an increase in temperature, rated by how much current causes them to heat up to a predetermined amount of degrees above ambient temperature. The amount of temperature rise above ambient (i.e., when no current flows) determines the current rating of a conductor. For example, when a conductor reaches $70^{\circ} \mathrm{C}$ above ambient, the conductor is said to be at full load rating [1].

Scientists used to mention the dynamic thermal rating in literature. Conductors transporting energy in low temperatures are more efficient. For an overhead transmission line, the maximum temperature it supports is $80 \mathrm{C}^{\circ}$ [4-6]. The conductor transmitting 700 amperes at $40 \mathrm{C}$; can transport 1200 amperes at $10 \mathrm{C}^{\circ}$, which implies, from summer season to winter; transmission line capacity can reach the double $[4,6,7]$. 
The conductor temperature varies in the range of $0 \circ$ to $60{ }^{\circ} \mathrm{C}$ or even larger, resulting changes of the line resistance $[3,8,9]$.

Meanwhile, the resistance fluctuations are explicitly taken into account and coupled to power flow analysis. Power flow fluctuations can cause various phenomena ranging from frequency and voltage stability, Thermal contingency, to critical scenarios such as components outages and black out [10]. For the purposes of load flow determination and system state estimation, a variety of methods has been used. The development of these methods is mainly led by the basic requirements of load flow calculation, which can be summed up as

a. the convergence properties

b. the computing efficiency and memory requirements

c. the convenience and flexibility of the implementation

Mathematically, the load flow problem is a problem of solving a system of nonlinear algebraic equations. With the scale of power system continually expanding, the dimension of load flow equations now becomes very high, thus research is still very active. Newton Raphson technique stands to be the most important approach to solve the load flow. Moreover this accurate technique became unacceptable for realtime electric power system operation (dynamic), the problems result mainly from the speed of operation and the dependability (no missing operations), hence the introduction of the artificial intelligence or more precising extreme learning machine due to its extremely fast training, good generalization, and universal approximation /classification capability [11]. It has been demonstrated to have excellent learning accuracy /speed in various applications, such as face classification, image segmentation, human action recognition, prediction, and functions approximation. ELM offers effective solutions for the electric power system as it is demonstrated; in the article [12] a novel version of ELM, which can be applied to train a single hidden layer recurrent neural network. ELM was presented and employed in order to achieve higher forecasting electricity load accuracy. In [13] authors introduced an ELM-based predictor, then it was developed for the power system. The predictor has been used for real-time to enhance the dynamic security of the power systems. Article [14] explores a fault diagnosis method for the key mechanical components of the wind turbine. The method based on improved extreme learning machine (IELM) combined the fault characteristics of gear and bearing of wind turbine drive system. A robust observer to detect and isolate sensors fault in a variable speed wind turbine is discussed in [15]. The designed approach was based on the ELM algorithm for the prediction of unknown model dynamics to design the robust non-linear observer. The article [16] envisages the application of craziness-based PSO to enhance the performance of ELM for feature classification of single and combined power quality disturbances. Thus we introduced this fast and accurate approach in this paper to examine the variation of the transported power, load flow and losses due to the influence of temperature on conductor resistance. To start with, we attempted to study the first proposition which is the neural network Then for further optimization and in terms of precision, exactness, and proficiency extreme learning machine algorithm was applied to address the above problem.

\section{RESEARCH METHOD}

\subsection{Neural networks}

The origin of artificial neural networks comes from the biological neuron modeling test by Warren McCulluch and Walter Pitts. Initially Neural networks objective was: patterns recognition, classification then it becomes very interesting in all domains [17].

\subsubsection{Neuron Model}

Indeed; the simple architecture of a single neuron with a single layer is composed essentially:

First, the scalar input $p$ which is multiplied by the scalar weight $w$ to form the product $w p$ this operation takes place at the integrator which is one of the important parts of the neuron; the result is again a scalar added to a scalar bias $b$ to form the net input $n$.

The result $n$ is then transformed by a transfer function $f$ which produces the neuron output $a$. [18, $19]$, the model is shown in Figure 1. 


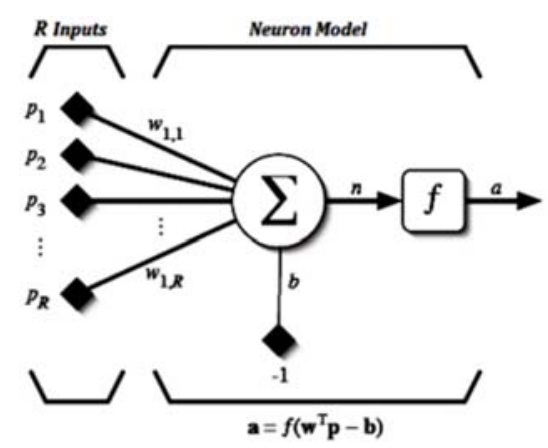

Figure 1. Artificial neuron model

$$
n=\sum_{j=1}^{R} w_{1, j} p-b
$$

\subsubsection{Neural Network Learning}

Learning is a process by which the free parameters from a neural network are adapted, through a simulation process by the environment in which the network is contained $[17,19,20]$

The supervised and unsupervised methods are essentially the two types of learning for a neural network. In our case, we are going to use the supervised learning where the training is controlled by an external agent who watches the answer that the network supposed to generate from the determined entrance. The supervisor compares the output of the network with the expected one and determines the amount of modifications to be made on the weights $[18,21,22]$.

The supervised learning can be done through the three following Paradigms:

a. Error correction learning

b. Reinforcement learning

c. Stochastic learning.

During the artificial neural network training by error correction, the weights of the communication links are adjusted trying to minimize a function of cost depending on the difference between the desired values and the obtained one from the output network [19, 23].

It is required to determine the modifications on weights using the committed error, the correction error is calculated as the following expression:

$\Delta w_{k i}=\eta y_{j}\left(d_{k}-y_{k}\right)$

Where:

$\Delta w_{k i}$ is the weight variation of the connection between the neurons $j$ from the anterior layer and the output layer node $k$.

$y_{k}:$ the desired neuron output.

$y_{j}$, and $y_{k}$ are the output values produced in the neuron $i$ and $k$ respectively.

$\eta$ a positive factor denominated the learning rate $0<\eta<1[18,24,25]$.

We can say that the new weight is proportional to the committed error produced by the network and the answer of the node $\mathrm{j}$ in the previous layer as shown in the following formula:

$$
w_{k j}^{\text {actual }}=\Delta w_{k j}+w_{k j}^{\text {anterior }}
$$

The total error is known as the mean squared error expressed in the equation (4) $[26,27]$ :

Where:

$$
\text { Error }_{\text {global }}=\frac{1}{2 P} \sum_{P=1}^{P} \sum_{K=1}^{N}\left(y_{k}^{(p)}-d_{k}^{(p)}\right)
$$

$\mathrm{N}$ is the number of neurons in the output layer and $\mathrm{P}$ is the number of examples in the training sample. Normally to minimize this criterion function, is employed learning rule given by the descending gradient [18, 19].

$$
\Delta w_{k j}=-\eta \nabla_{\mathrm{w}_{\mathrm{kj}}}\left(\text { Error }_{\text {global }}\right)
$$


If $(\eta)$ takes a little value the learning process is made smoothly which gives; as a result, an increment in the time of convergence to a stable solution. In the other hand if $\eta$ has an important value the speed of learning gets increased but there will be a divergence risk and this causes the instability of the system [25-27].

\subsection{Extreme Learning Machine ELM}

Huang et al. proposed an extreme learning machine algorithm, as a new learning scheme working for single hidden layer feed-forward networks (SLFNs) [28,29].ELM is entirely different from traditional iterative learning algorithms as it randomly selects the input weights $(W)$ and biases $(b)$ for hidden nodes and analytically calculates the output weights $(\beta)$ by finding the least square solution.

In doing so, it is proven that the training error can still be minimized with even better generalization performance [30]. Notably, the learning speed of ELM can be thousands of times faster than traditional feedforward network learning algorithms like BP algorithm. Compared with conventional learning algorithms, ELM not only tends to reach the smallest training error but also to obtain the smallest norm of weights [29, 31].

For $N$ arbitrary distinct samples $\left(x_{i}, t_{i}\right)$ where:

$$
\begin{aligned}
x_{i} & =\left(x_{i 1}, x_{i 2}, \ldots . ., x_{i n}\right)^{T} \in R^{n} \\
t_{i} & =\left(t_{i 1}, t_{i 2}, \ldots . ., t_{i m}\right)^{T} \in R^{m}
\end{aligned}
$$

Standard SFLNs with $N \approx$ nodes and activation function $g(x)$ are mathematically modeled as:

$$
j=1, \ldots, N
$$

$$
\sum_{i=1}^{N \approx} \beta_{i} g\left(w_{i} \cdot x_{j}+b_{i}\right)=o_{j}
$$

Where $w_{i}=\left(w_{i 1}, w_{i 2}, \ldots ., w_{i n}\right)^{T}$ is the weight vector connection ( $\left.i t h\right)$ hidden node and input nodes.

$\beta_{i}=\left(\beta_{i 1}, \beta_{i 2}, \ldots \ldots, \beta_{i m}\right)^{T}$ is the weight vector connecting the $(i t h)$ hidden node and output nodes, and $b_{i}$ : is the threshold of the (ith) hidden node. $w_{i} \cdot x_{j}$ denotes the inner product of $w_{i}$ and $x_{j}$.

That standard SFLN with $N \approx$ hidden nodes and $g(x)$ activation function can approximate these $N$ samples with zero.

$$
\sum_{j=1}^{N \approx}\left\|o_{j}-t_{j}\right\|=0
$$

What means there exist $\beta_{i}, w_{i}$ and $b_{i}$ such that:

$$
\sum_{i=1}^{N^{\approx}} \beta_{i} g_{i}\left(x_{j}\right)=\sum_{i=1}^{N^{\approx}} \beta_{i} g\left(w_{i} \cdot x_{j}+b_{i}\right)=t_{j}
$$

Equation (10) can be written compactly as

Where :

$$
H \beta=T
$$

$$
\begin{aligned}
& H\left(w_{1} \ldots w_{N}, x_{1} \ldots x_{N}, b_{1} \ldots b_{N} \approx\right)=\left[\begin{array}{ccc}
g\left(w_{1} \cdot x_{1}+b_{1}\right) & \ldots & g\left(w_{N} \approx x_{1}+b_{N} \approx\right) \\
\vdots & \ldots & \vdots \\
g\left(w_{1} \cdot x_{N}+b_{1}\right) & \ldots & g\left(w_{N} \approx \cdot x_{N}+b_{N} \approx\right)
\end{array}\right]_{\mathrm{N} * N^{\approx}} \\
& \beta=\left[\begin{array}{c}
\beta_{1} \\
\vdots \\
\beta_{N} \approx
\end{array}\right]_{N \approx * m}^{T} \text { and } T=\left[\begin{array}{c}
t_{1} \\
\vdots \\
t_{N}
\end{array}\right]_{N * m}^{T}
\end{aligned}
$$

Thus, the extreme learning machine algorithm can be summarized as follows:

Step 1:Randomly assign input weight $W_{i}$ and bias $b_{i},(i=1,2, ., N)$.

Step2: Calculate the hidden layer output matrix $\mathrm{H}$.

Step3: Calculate the output weight $\beta$ by $\beta=\mathrm{H}^{\dagger} \mathrm{T}$

If hidden layer output matrix is non-square (that means $N^{\approx}<N$ ), the determinant of $H \operatorname{det}(H)=0$ and (rank $\mathrm{H}<N^{\approx}$ ), in linear algebra matrix, is assessed as a singular matrix that cannot be directly inverted [3234].

$$
\beta=\left(\mathrm{H}^{T} \mathrm{H}\right)^{-1} \mathrm{H}^{T} \mathrm{~T}
$$

The inverse of $H$ cannot be determined if $H$ is not a full-rank matrix. In this case, the generalized inverse matrix, known as pseudo inverse, is used. In order to calculate the pseudo inverse, various approaches 
can be used. The most widely known type is the Moore-Penrose pseudo-inverse [35]. The pseudo-inverse of the matrix $H$, namely $H^{\dagger}$, can be computed via least square solution:

$$
H^{\dagger}=\left(H^{T} H\right)^{-1} H
$$

This solution is accurate as long as the square matrix $\left(H^{T} H\right)$ is invertible. However, it is singular in some applications. In SLFN, it is singular in most of the cases since there is a tendency to select $m<<n$. In ELM, Huang et al., have solved this problem using Moore- Penrose pseudo inverse of $\mathrm{H}$ matrix to overcome this problem $[32,36,37]$.

\section{RESULTS AND ANALYSIS}

In order to verify the proposed two approaches; ELM and neural networks, the paper study is conducted on IEEE 30 bus test system shown in Figure 2, it comprises of 6 generators, bus number one (1) is considered as a slack bus. Likewise, 24 loads powered over 41 transmission lines.

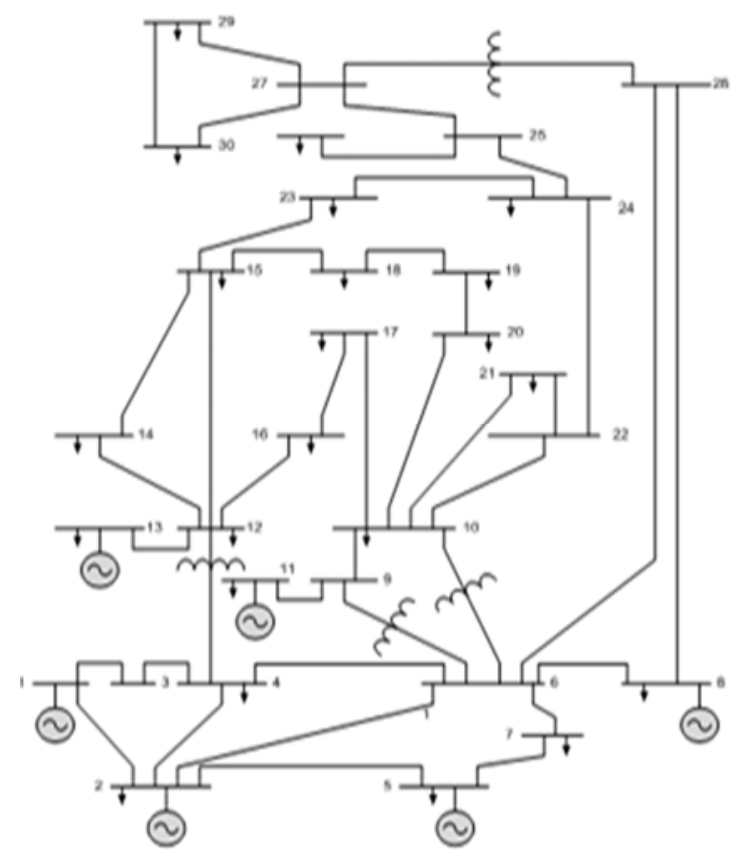

Figure 2. Single Line Diagram of IEEE-30bus [38]

\subsection{Line Flow Solution Using Newton-Raphson Algorithm}

Table 1 displayed the line flow results at $25 \mathrm{C}^{\circ}$. It is the initial step to provide, active and reactive power and the total system lossesThe whole system is operating under normal conditions. These results are used to be the input matrix for the neural network training phase.

Table 1. The line flow and losses at $\mathrm{T}=25 \mathrm{C}^{\circ}$

\begin{tabular}{cccccccccccc}
\hline i to j & $\begin{array}{c}\text { P } \\
\text { (MW) }\end{array}$ & $\begin{array}{c}\text { Q } \\
\text { (MVAR) }\end{array}$ & $\begin{array}{c}\text { S } \\
\text { (MVA) }\end{array}$ & $\begin{array}{c}\text { Losses } \\
\text { (MW) }\end{array}$ & $\begin{array}{c}\text { Losses } \\
\text { (Mvar) }\end{array}$ & i to j & $\begin{array}{c}\text { P } \\
\text { (MW) }\end{array}$ & $\begin{array}{c}\text { Q } \\
\text { (MVAR) }\end{array}$ & $\begin{array}{c}\text { S } \\
\text { (MVA) }\end{array}$ & $\begin{array}{c}\text { Losses } \\
\text { (MW) }\end{array}$ & $\begin{array}{c}\text { Losses } \\
\text { (Mvar) }\end{array}$ \\
\hline $1-2$ & 177,778 & $-22,148$ & 179,152 & 5,464 & 10,524 & $12-13$ & 0,000 & $-10,291$ & 10,291 & 0,000 & 0,133 \\
$1-3$ & 83,221 & 5,127 & 83,378 & 2,808 & 7,085 & $12-14$ & 7,856 & 2,442 & 8,227 & 0,075 & 0,155 \\
$2-4$ & 45,712 & 2,705 & 45,792 & 1,106 & $-0,517$ & $12-15$ & 17,857 & 6,947 & 19,161 & 0,217 & 0,428 \\
$2-5$ & 82,990 & 1,703 & 83,008 & 2,995 & 8,178 & $12-16$ & 7,208 & 3,363 & 7,954 & 0,053 & 0,112 \\
$2-6$ & 61,912 & $-0,958$ & 61,920 & 2,048 & 2,264 & $14-15$ & 1,582 & 0,687 & 1,724 & 0,006 & 0,005 \\
$3-4$ & 78,012 & $-3,158$ & 78,076 & 0,771 & 1,344 & $15-18$ & 6,014 & 1,744 & 6,262 & 0,039 & 0,080 \\
$4-6$ & 70,126 & $-17,526$ & 72,282 & 0,604 & 1,179 & $15-23$ & 5,001 & 2,956 & 5,810 & 0,031 & 0,063 \\
$4-12$ & 44,121 & 14,646 & 46,489 & 0,000 & 4,685 & $16-17$ & 3,654 & 1,451 & 3,932 & 0,012 & 0,027 \\
\hline
\end{tabular}

Int J Pow Elec \& Dri Syst, Vol. 10, No. 3, Sep 2019: 1244 - 1254 


\begin{tabular}{|c|c|c|c|c|c|c|c|c|c|c|c|}
\hline $\mathrm{i}$ to $\mathrm{j}$ & $\begin{array}{c}\mathrm{P} \\
(\mathrm{MW})\end{array}$ & $\begin{array}{c}\mathrm{Q} \\
\text { (MVAR) }\end{array}$ & $\begin{array}{c}\mathrm{S} \\
\text { (MVA) }\end{array}$ & $\begin{array}{l}\text { Losses } \\
\text { (MW) }\end{array}$ & $\begin{array}{l}\text { Losses } \\
\text { (Mvar) }\end{array}$ & $\mathrm{i}$ to $\mathrm{j}$ & $\begin{array}{c}\mathrm{P} \\
(\mathrm{MW})\end{array}$ & $\begin{array}{c}\mathrm{Q} \\
\text { (MVAR) }\end{array}$ & $\begin{array}{c}\mathrm{S} \\
\text { (MVA) }\end{array}$ & $\begin{array}{l}\text { Losses } \\
\text { (MW) }\end{array}$ & $\begin{array}{l}\text { Losses } \\
\text { (Mvar) }\end{array}$ \\
\hline $5-7$ & $-14,205$ & 10,500 & 17,664 & 0,151 & $-1,687$ & $18-19$ & 2,775 & 0,765 & 2,879 & 0,005 & 0,010 \\
\hline $6-7$ & 37,523 & $-1,885$ & 37,570 & 0,367 & $-0,598$ & $19-20$ & $-6,730$ & $-2,645$ & 7,231 & 0,017 & 0,034 \\
\hline $6-8$ & 29,528 & $-3,754$ & 29,766 & 0,103 & $-0,558$ & $21-22$ & $-1,877$ & $-1,594$ & 2,462 & 0,001 & 0,001 \\
\hline $6-9$ & 27,693 & $-7,322$ & 28,644 & 0,000 & 1,594 & $22-24$ & 5,654 & 2,788 & 6,304 & 0,043 & 0,067 \\
\hline $6-10$ & 15,823 & 0,653 & 15,836 & 0,000 & 1,278 & $23-24$ & 1,770 & 1,293 & 2,192 & 0,006 & 0,012 \\
\hline $6-28$ & 18,819 & $-9,618$ & 21,134 & 0,060 & $-13,086$ & $24-25$ & $-1,325$ & 1,602 & 2,079 & 0,008 & 0,014 \\
\hline 8- 28 & $-0,575$ & $-2,370$ & 2,438 & 0,000 & $-4,368$ & $25-26$ & 3,545 & 2,366 & 4,262 & 0,045 & 0,066 \\
\hline $9-11$ & 0,000 & $-15,657$ & 15,657 & 0,000 & 0,462 & $25-27$ & $-4,877$ & $-0,778$ & 4,939 & 0,026 & 0,049 \\
\hline $9-10$ & 27,693 & 6,741 & 28,501 & 0,000 & 0,809 & $27-28$ & $-18,184$ & $-4,157$ & 18,653 & $-0,000$ & 1,309 \\
\hline $10-20$ & 9,027 & 3,560 & 9,704 & 0,081 & 0,180 & $27-29$ & 6,189 & 1,668 & 6,410 & 0,086 & 0,162 \\
\hline $10-17$ & 5,372 & 4,414 & 6,953 & 0,014 & 0,037 & $27-30$ & 7,091 & 1,661 & 7,283 & 0,161 & 0,304 \\
\hline $10-21$ & 15,733 & 9,842 & 18,558 & 0,110 & 0,237 & $29-30$ & 3,704 & 0,606 & 3,753 & 0,033 & 0,063 \\
\hline $10-22$ & 7,583 & 4,490 & 8,813 & 0,052 & 0,107 & Total loss & & & & 17,599 & 22,244 \\
\hline
\end{tabular}

\subsection{The Neural Network}

\subsubsection{The training phase using Levenberg- Marquard algorithm}

a. The training algorithm is Levenberg-Marquard (trainlm), as it is shown in (Figure 3).

b. The performance is the mean squared error (mse) (Figure 4).

c. The convergence is satisfied at $\mathrm{t}=15 \mathrm{sec}$ (Figure 3 ).

d. The performance value reached 3.15e-19 (Figure 4).

In tables 1 and 2 and also (Figure 5), it is evident that the neural network outputs and targets are completely identical. The main squared error reaches the value 3.15e-19 (Figure 4). Bias and weights are adjusted.

Here below we can see clearly the neural network architecture and training phase exposed in Figures 3 , the performance in Figure 4 and the regression in Figure 5 respectively.

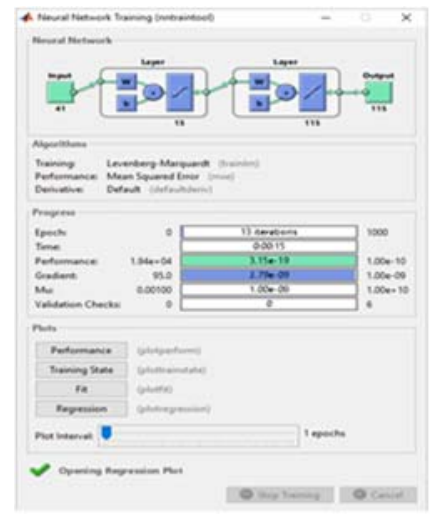

Figure 3. N.N architecture and training phase

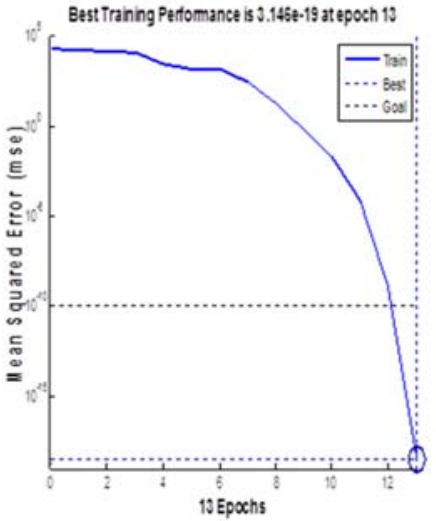

Figure 4. Performance

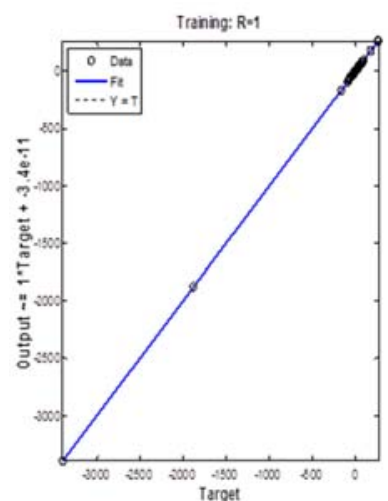

Figure 5. Regression

Table2. Line flow based on a neural network at $25 \mathrm{C}^{\circ}$

\begin{tabular}{cccccccccc}
\hline i to $\mathrm{j}$ & $\begin{array}{c}\mathrm{P} \\
\text { (MW) }\end{array}$ & $\begin{array}{c}\mathrm{Q} \\
\text { (MVAR) }\end{array}$ & $\begin{array}{c}\text { Losses } \\
\text { (MW) }\end{array}$ & $\begin{array}{c}\text { Losses } \\
\text { (Mvar) }\end{array}$ & i to j & $\begin{array}{c}\text { P } \\
\text { (MW) }\end{array}$ & $\begin{array}{c}\text { Q } \\
\text { (MVAR) }\end{array}$ & $\begin{array}{c}\text { Losses } \\
\text { (MW) }\end{array}$ & $\begin{array}{c}\text { Losses } \\
\text { (Mvar) }\end{array}$ \\
\hline $1-2$ & 177,778 & $-22,148$ & 5,464 & 10,524 & $12-13$ & $1,705 \mathrm{e}-13$ & $-10,291$ & $1,421 \mathrm{e}-14$ & 0,133 \\
$1-3$ & 83,221 & 5,127 & 2,808 & 7,085 & $12-14$ & 7,856 & 2,442 & 0,075 & 0,155 \\
$2-4$ & 45,712 & 2,705 & 1,106 & $-0,517$ & $12-15$ & 17,857 & 6,947 & 0,217 & 0,428 \\
$2-5$ & 82,990 & 1,703 & 2,995 & 8,178 & $12-16$ & 7,208 & 3,363 & 0,053 & 0,112 \\
$2-6$ & 61,912 & $-0,958$ & 2,048 & 2,264 & $14-15$ & 1,582 & 0,687 & 0,006 & 0,005 \\
$3-4$ & 78,012 & $-3,158$ & 0,771 & 1,344 & $15-18$ & 6,014 & 1,744 & 0,039 & 0,080 \\
$4-6$ & 70,126 & $-17,526$ & 0,604 & 1,179 & $15-23$ & 5,001 & 2,956 & 0,031 & 0,063 \\
$4-12$ & 44,121 & 14,646 & $7,105 \mathrm{e}-15$ & 4,685 & $16-17$ & 3,654 & 1,451 & 0,012 & 0,027 \\
$5-7$ & $-14,205$ & 10,500 & 0,151 & $-1,687$ & $18-19$ & 2,775 & 0,765 & 0,005 & 0,010 \\
$6-7$ & 37,523 & $-1,885$ & 0,367 & $-0,598$ & $19-20$ & $-6,730$ & $-2,645$ & 0,017 & 0,034 \\
$6-8$ & 29,528 & $-3,754$ & 0,103 & $-0,558$ & $21-22$ & $-1,877$ & $-1,594$ & 0,001 & 0,001 \\
$6-9$ & 27,693 & $-7,322$ & $-7,105 \mathrm{e}-14$ & 1,594 & $22-24$ & 5,654 & 2,788 & 0,043 & 0,067 \\
$6-10$ & 15,823 & 0,653 & $-7.993 \mathrm{e}-15$ & 1,278 & $23-24$ & 1,770 & 1,293 & 0,006 & 0,012 \\
\hline
\end{tabular}

Power flow variation based on extreme learning machine algorithm in power system (Labed Imen) 


\begin{tabular}{cccccccccc}
\hline i to $\mathrm{j}$ & $\begin{array}{c}\mathrm{P} \\
\text { (MW) }\end{array}$ & $\begin{array}{c}\text { Q } \\
\text { (MVAR) }\end{array}$ & $\begin{array}{c}\text { Losses } \\
\text { (MW) }\end{array}$ & $\begin{array}{c}\text { Losses } \\
\text { (Mvar) }\end{array}$ & i to j & $\begin{array}{c}\text { P } \\
\text { (MW) }\end{array}$ & $\begin{array}{c}\text { Q } \\
\text { (MVAR) }\end{array}$ & $\begin{array}{c}\text { Losses } \\
\text { (MW) }\end{array}$ & $\begin{array}{c}\text { Losses } \\
\text { (Mvar) }\end{array}$ \\
\hline $6-28$ & 18,819 & $-9,618$ & 0,060 & $-13,086$ & $24-25$ & $-1,325$ & 1,602 & 0,008 & 0,014 \\
$8-28$ & $-0,575$ & $-2,370$ & $8,881 \mathrm{e}-14$ & $-4,368$ & $25-26$ & 3,545 & 2,366 & 0,045 & 0,066 \\
$9-11$ & $-2.273 \mathrm{e}-13$ & $-15,657$ & $-1.421 \mathrm{e}-14$ & 0,462 & $25-27$ & $-4,877$ & $-0,778$ & 0,026 & 0,049 \\
$9-10$ & 27,693 & 6,741 & 0,000 & 0,809 & $27-28$ & $-18,184$ & $-4,157$ & $-1,421 \mathrm{e}-14$ & 1,309 \\
$10-20$ & 9,027 & 3,560 & 0,081 & 0,180 & $27-29$ & 6,189 & 1,668 & 0,086 & 0,162 \\
$10-17$ & 5,372 & 4,414 & 0,014 & 0,037 & $27-30$ & 7,091 & 1,661 & 0,161 & 0,304 \\
$10-21$ & 15,733 & 9,842 & 0,110 & 0,237 & $29-30$ & 3,704 & 0,606 & 0,033 & 0,063 \\
$10-22$ & 7,583 & 4,490 & 0,052 & 0,107 & Total loss & & & 17,599 & 22,244 \\
\hline
\end{tabular}

The $\mathrm{NN}$ is trained and ready to be utilized in real time for resistance variation $\mathrm{R}_{\mathrm{T}=30 \mathrm{C}^{\circ}}$ and $\mathrm{R}_{\mathrm{T}=05 \mathrm{C}^{\circ}}$. Line flow results using the neural network approach are exposed in Table 3 for the two resistance Values $\mathrm{R}_{\mathrm{T}=30 \mathrm{C}^{\circ}}$ and $\mathrm{R}_{\mathrm{T}=05 \mathrm{C}^{\circ} \text {. }}$.

Table 3. Line flow using the trained neural network in real time $\left(\mathrm{T}=30 \mathrm{C}^{\circ}\right.$ and $\left.\mathrm{T}=5 \mathrm{C}^{\circ}\right)$

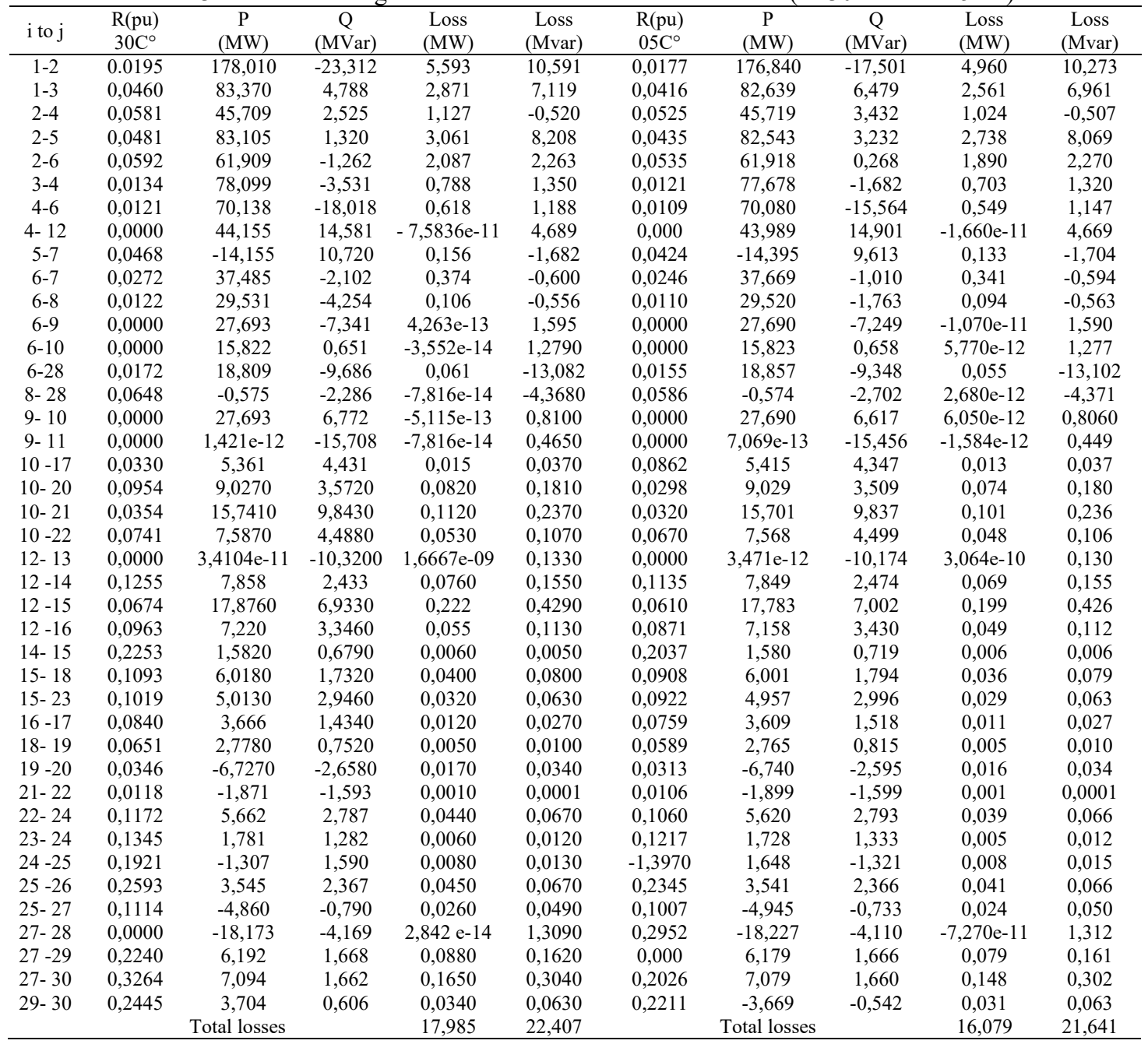

\subsection{Extreme learning machine algorithm}

3.3.1. Training-validation and test

The ELM training -validation and test process is exposed in Figure 6, the performance in Figure 7, and the regression in Figure 8 respectively. 


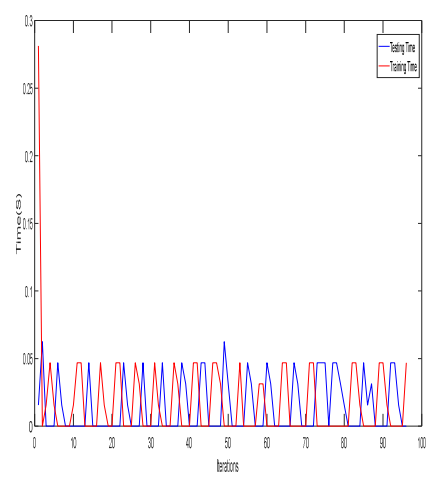

Figure 6. Training and Testing Time

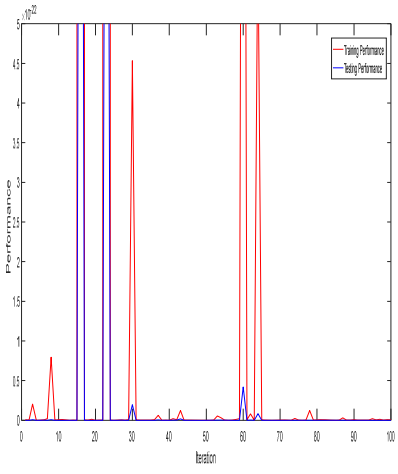

Figure 7. Performance

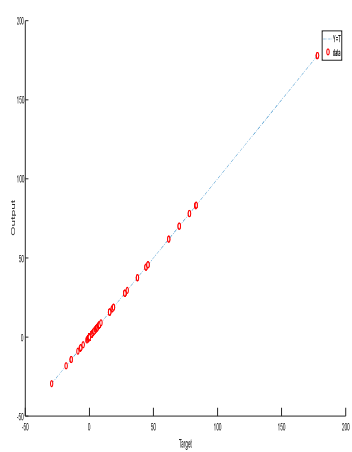

Figure 8. Regression

Table 4 illustrates ELM training phase parameters.

Table 4. ELM training phase parameters

\begin{tabular}{cc}
\hline Extreme learning machine & Values \\
\hline Training time(s) & 0,0469 \\
Testing time(s) & 0,0000 \\
Training performance & $3,666 \mathrm{e}-25$ \\
Testing performance & $8,248 \mathrm{e}-27$ \\
\hline
\end{tabular}

ELM model is built and ready to be used in real time.

Table 5 shows the line flow results provided by the ELM trained model for the two resistance variation: $\mathrm{R}_{\mathrm{T}=30 \mathrm{C}^{\circ}}$ and $\mathrm{R}_{\mathrm{T}=05 \mathrm{C}^{\circ}}$

Table 5. Line flow based on Extreme learning machine algorithm in real time $\left(\mathrm{T}=30 \mathrm{C}^{\circ}\right.$ and $\left.\mathrm{T}=5 \mathrm{C}^{\circ}\right)$

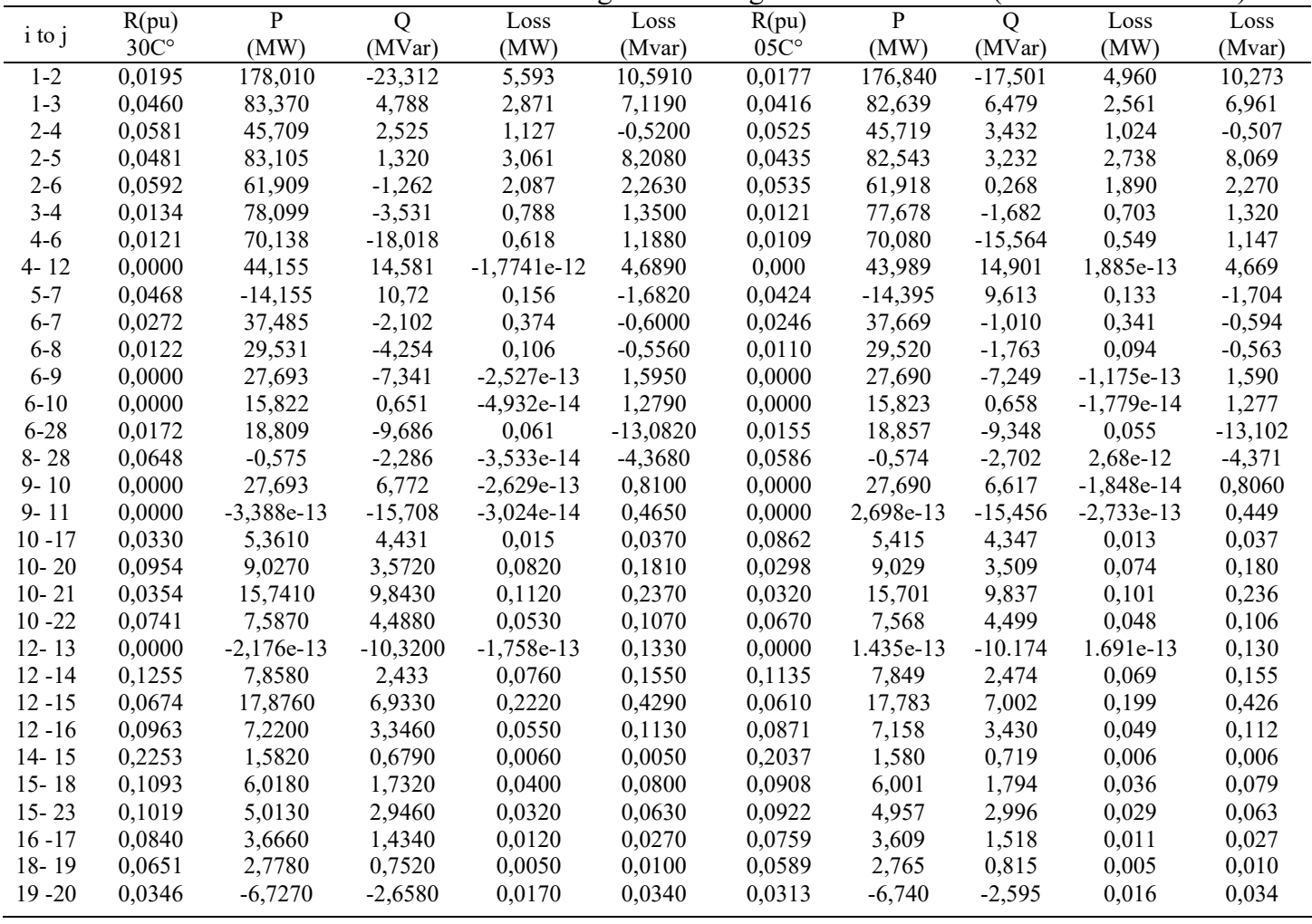

Power flow variation based on extreme learning machine algorithm in power system (Labed Imen) 


\begin{tabular}{|c|c|c|c|c|c|c|c|c|c|c|}
\hline $\mathrm{i}$ to $\mathrm{j}$ & $\begin{array}{l}\mathrm{R}(\mathrm{pu}) \\
30 \mathrm{C}^{\circ}\end{array}$ & $\begin{array}{c}\mathrm{P} \\
(\mathrm{MW})\end{array}$ & $\begin{array}{c}\mathrm{Q} \\
\text { (MVar) }\end{array}$ & $\begin{array}{l}\text { Loss } \\
\text { (MW) }\end{array}$ & $\begin{array}{c}\text { Loss } \\
\text { (Mvar) }\end{array}$ & $\begin{array}{l}\mathrm{R}(\mathrm{pu}) \\
05 \mathrm{C}^{\circ}\end{array}$ & $\begin{array}{c}\mathrm{P} \\
(\mathrm{MW})\end{array}$ & $\begin{array}{c}\mathrm{Q} \\
\text { (MVar) }\end{array}$ & $\begin{array}{c}\text { Loss } \\
(\mathrm{MW})\end{array}$ & $\begin{array}{c}\text { Loss } \\
\text { (Mvar) }\end{array}$ \\
\hline $21-22$ & 0,0118 & $-1,8710$ & $-1,5930$ & 0,0010 & 0,0001 & 0,0106 & $-1,899$ & $-1,599$ & 0,001 & 0,0001 \\
\hline $22-24$ & 0,1172 & 5,6620 & 2,7870 & 0,0440 & 0,0670 & 0,1060 & 5,620 & 2,793 & 0,039 & 0,066 \\
\hline $24-25$ & 0,1921 & $-1,3070$ & 1,5900 & 0,0060 & 0,0130 & $-1,3970$ & 1,648 & $-1,321$ & 0,008 & 0,015 \\
\hline $25-26$ & 0,2593 & 3,5450 & 2,3670 & 0,0400 & 0,0670 & 0,2345 & 3,541 & 2,366 & 0,041 & 0,066 \\
\hline $25-27$ & 0,1114 & $-4,8600$ & $-0,7900$ & 0,0320 & 0,0490 & 0,1007 & $-4,945$ & $-0,733$ & 0,024 & 0,050 \\
\hline $27-29$ & 0,2240 & 6,1920 & 1,6680 & 0,0050 & 0,1620 & 0,0000 & 6,179 & 1,666 & 0,079 & 0,161 \\
\hline $27-30$ & 0,3264 & 7,0940 & 1,6620 & 0,0170 & 0,3040 & 0,2026 & 7,079 & 1,660 & 0,148 & 0,302 \\
\hline \multirow[t]{2}{*}{$29-30$} & 0,2445 & 3,7040 & 0,6060 & 0,0340 & 0,0630 & 0,2211 & $-3,669$ & $-0,542$ & 0,031 & 0,063 \\
\hline & & Total losses & & 17,9850 & 22,4070 & & Total losses & & 16,079 & 21,641 \\
\hline
\end{tabular}

\subsection{Discussion of results}

\subsubsection{Neural networks}

This case study demonstrates the application and practical benefits of the neural network with backpropagation, as it is introduced here to solve a nonlinear problem which is the variation of the conductor resistance due to the temperature fluctuations and its influence on the power flow and losses changes; attempting to optimize the time of simulation.

The Newton raphson method generated the dataset to be used for the training patterns process. The input matrix is composed of; line resistance $(\mathrm{R})$, load demand $\left(\mathrm{P}_{\mathrm{D}}\right),\left(\mathrm{Q}_{\mathrm{D}}\right)($ real and reactive power), bus voltage magnitude $\left(\mathrm{V}_{\mathrm{i}}\right)$. The neural network model developed for IEEE 30 bus test was trained to provide power system values which are power generation (real and reactive power $)\left(\mathrm{P}_{\mathrm{g}}\right),\left(\mathrm{Q}_{\mathrm{g}}\right)$ and system losses $\left(\mathrm{P}_{\mathrm{ij}}\right)$, $\left(\mathrm{Q}_{\mathrm{ij}}\right)$ (real and reactive).

The training phase took $15 \mathrm{~s}$ to meet the convergence (Figure 3), the performance reached the best value $3.15 \mathrm{e}-19$ at $15 \mathrm{~s}$ (Figure 4). The network parameters are adjusted (bias and weights) and it is ready to be utilized in real time (for the two different values of temperature: $\mathrm{T} 1=30 \mathrm{C}^{\circ}$ and $\mathrm{T} 2=05 \mathrm{C}^{\circ}$ ).

The conductor's resistance increases as its temperature increases and so losses, due to; either the current load or the weather conditions. Results shown in (Table 3) are acquired in milliseconds (neural network results). The objective of work is to minimize time by utilizing the neural network for such changing of temperature. Also to assess the generated powers and losses during the 24 hours per day and through the entire year within milliseconds.

\subsubsection{Extreme learning machine}

Most of our effort has focused on Extreme learning machine algorithm in this paper. Even for ELM the simulation process containing two steps; the training-validation and the test phase. The dataset is randomly partitioned into two non-overlapped sets, to form the input training -validation matrix and the test one. The input matrix is composed of line resistance $\mathrm{R}$, load demand (real and reactive power) $\left(\mathrm{P}_{\mathrm{D}}\right),\left(\mathrm{Q}_{\mathrm{D}}\right)$, bus voltage magnitude $\left(\mathrm{V}_{\mathrm{i}}\right)$. The target matrix is containing power generation (real and reactive power)) $\left(\mathrm{P}_{\mathrm{g}}\right),\left(\mathrm{Q}_{\mathrm{g}}\right)$ and system losses (real and reactive) $\left(\mathrm{P}_{\mathrm{ij}}\right),\left(\mathrm{Q}_{\mathrm{ij}}\right)$. The algorithm seems to be very fast, it achieves the highest accuracy $10^{-27}$ (Figure 13) and fastest training time: $0.0469(\mathrm{~S})$ and also testing time $0(\mathrm{~S})$ (figure 12).

In order to further verify the validity of the improved built model, and the generalization; two extreme values of the resistance $30 \mathrm{C}^{\circ}$ and $05 \mathrm{C}$ are introduced, results are displayed in Table 4 .

According to ELM based power flow, we estimated to match results offered by the neural network with further optimization in time and more exactitude (Table 5). It is evident that the regression accuracy of ELM algorithm is superior to the NN.

Losses at:

$\mathrm{T}=25 \mathrm{C}^{\circ}$ are $17,599 \mathrm{MW}, 22,244 \mathrm{Mvar}$.

$\mathrm{T}=30 \mathrm{C}^{\circ}$ are $17,985 \mathrm{MW}, 22,407 \mathrm{Mvar}$.

$\mathrm{T}=05 \mathrm{C}^{\circ}$ are $16,79 \mathrm{MW}, 21,641 \mathrm{Mvar}$.

Mathematically losses are covered by the plant connected to the slack bus (slack number one 1), but in the real interconnected power system; the slack bus generator is not always a single equivalent machine located in a control area, losses can be interpreted as exchanges and power transactions across multi-area systems. This may impose an additional operating cost. The price increases as well as the slack bus production increases.

ELM makes an improvement in the electrical system response; the grid parameters can be prevented instantly at any moment, and the plants generation can be rescheduled to meet load demand (in addition to losses), to maintain power system security, to avoid contingencies and load shedding (voltage drop,

Int J Pow Elec \& Dri Syst, Vol. 10, No. 3, Sep 2019: 1244 - 1254 
frequency fluctuation), to prevent system violations and overloads, to predict the effect of outages and to minimize the fuel consumption.

Additionally, ELM could likewise be extended to make use of a large scale database, (Within [05 30] $\mathrm{C}^{\circ}$ ), cause it is already trained, and also for more advanced complications in power system.

Table 6 lists the mean comparison results of ANN and ELM. Extreme Learning Machines (ELMs) are very controversial and very fast machine learning models that perform very well. ELM results are better than ANN, due to the ability of the excellent generalization performance and the learning speed which can be thousands of times faster than traditional neural networks.

Table 6.Comparison

\begin{tabular}{ccc}
\hline & Neural network & Extreme learning machine \\
\hline Training time(s) & 15 & 0,0469 \\
Testing time(s) & $/$ & 0,0000 \\
Training performance & $3,15 \mathrm{e}-19$ & $3,666 \mathrm{e}-25$ \\
Testing performance & $/$ & $8,248 \mathrm{e}-27$ \\
\hline
\end{tabular}

\section{CONCLUSION}

Power system security requires system monitoring in real time, where the database is continuously updated. This paper investigated the impact of the temperature variation on overhead power lines. This influence on the conductor's resistance cannot be neglected. We noticed different variations on the behavior of the electrical grid, notably: the system losses, the generated powers, and the line flow.

We introducedExtreme learning algorithm to solve this problem. The basic ANN modelization (feed forward back propagation) seems to be appropriate for the application IEEE 30 Bus system; but in terms of accuracy and exactitude of results offered by ELM (the timing minimization, performance), we can say economic objectives are realized (the optimization in time, fuel consumption and the reduction of the operation cost); ELM stands to be the most gifted version of the artificial intelligence techniques

\section{REFERENCES}

[1] W. B. Steven and M. E. El-Hawary, "Electric Power System Basics", Series Editor, IEEE PRESS, WileyInterscience a John Wiley \& Sons, INC, Publication. pp: 3.

[2] Michel Janssen and Christoph Lehner, the Cambridge Companion to Einstein, Volume 1.

[3] M. Bockarjova and G.Andersson, "Transmission Line Conductor Temperature Impact on State Estimation Accuracy," Power Tech, IEEE Lausanne, pp. 701-706, 2007.

[4] P. Dey et al., "Influence of conductor designs and operating temperature on the economics of overhead lines," PROC. IEE, vol. 118(3/4), 1971.

[5] Youmin Li et al.," An OPF Based Approach For Static Voltage Stability Evaluation Considering Heat Balance Rule Of Overhead Line," International Conference on Electric Utility Deregulation and Restructuring and Power Technologies November 26-2, Changsha, China, 2015.

[6] I. Albizu et al., "Tension -Temperature Behaviour of an Overhead Conductor in Operation," Reliability of Transmission and Distribution Networks, IETConference, 05 Apr 2012.

[7] L. Kotni., "A proposed algorithm for an overhead transmission line conductor temperature rise calculation," International Transaction on Electrical Energy Systems Int, vol. 24, pp. 578-59, 2014.

[8] A.Selakov et al., "Hybrid PSO-SVM method for short-term load forecasting during periods with significant temperature variations in city of Burbank", Applied Soft Computing, vol.16, pp. 80-88, 2014.

[9] M. M. Saied., "Assessing the dynamic rating of overhead transmission lines," European Transaction on Electrical Power, vol. 17, pp. 526-536, 2007.

[10] M. Schlapfer and P. Mancarella, "Probabilistic Modeling and Simulation of Transmission Line Temperatures under Fluctuating Power Flows," IEEE Transactions on Power Delivery, vol 26, no 4, pp. 2235 -2243.

[11] J. Tang et al.," Extreme Learning Machine for Multilayer Perceptron," IEEE Transactions on Neural Networks and Learning Systems, vol. 2 no. 4, pp. 809-821, 2016.

[12] Ö. F. Ertugrul., "Forecasting electricity load by a novel recurrent extreme learning machines approach," International Journal of Electrical Power \& Energy Systems, vol. 78, pp. 429-435, 2016.

[13] Xu, Y et al.," Extreme learning machine-based predictor for real-time frequency stability assessment of electric power systems," Neural Computing and Applications, vol. 22, no 3-4, pp. 501-508, 2012.

[14] Wu, B et al.," Fault diagnosis for wind turbine based on improved extreme learning machine," Journal of Shanghai Jiaotong University (Science), vol. 22, no. 4, pp. 466- 473, 2017.

[15] A. El Bakri, et al., "Extreme learning machine-based non-linear observer for fault detection and isolation of wind turbine," Australian Journal of Electrical and Electronics Engineering, pp. 1-9, 2019.

[16] S. Vidhya and V. Kamaraj," Particle swarm optimized extreme learning machine for feature classification in power quality data mining," Automatika, vol. 58, no. 4, pp. 487-494, 2017. 
[17] V. L. Paucar and M. J. Rider, "Artificial neural networks for solving the power flow problem in electric power systems," Electric Power Systems Research, vol. 62, pp. 139-144, 2002.

[18] D. Abdellah and L. Djamel, "Power System Economic Dispatch Using Traditional and Neural Networks Programs," International Journal of Scientific \& Engineering Research, vol. 3, no. 4, 2012.

[19] E. E. Elattar., "Prediction of wind power based on evolutionary optimized local general regression neural network," IET Gener. Transm. Distrib, vol. 8, no 5, pp. 916-923, 2014.

[20] W. Yixing et al., "Deep Learning Neural Network for Power System Fault Diagnosis," IEEE, Proceedings of the 35th Chinese Control Conference July 27-29, Chengdu, China, 2016.

[21] R. Aggarwal and Yonghua Song, "Artificial neural networks in power systems. II. Types of artificial neural networks," Power Engineering Journal, vol. 12, no 1, pp. 41-47, 1998.

[22] M.Safari and M.Sarvi, "Optimal load sharing strategy for the wind, a diesel battery hybrid power system based on imperialist competitive neural network algorithm," IET Renew. Power Gener, vol. 8, no. 8, pp. 937-946, 2014.

[23] L.G.Chen et al., "Group-based chaos genetic algorithm and a nonlinear ensemble of neural networks for short - term load forecasting," IET Gener. Transm. Distrib, \& the Institution of Engineering and Technology, pp. 1-8, 2016.

[24] N. Geetha, and P. Renuga, "Multilayer feed-forward neural network approach for optimal dispatch of UPFC embedded pool-bilateral electricity market, Ranking, "ETEP, vol. 12, no 2, 2002.

[25] L.A. Laboissiere, et al., "Maximum and minimum stock price forecasting of Brazilian power distribution companies based on artificial neural networks," Appl. Soft Comput. J. vol. 35, pp. 66-74, 2015.

[26] S.N. Singh and K.N. Srivastava, "Evolving Artificial Neural Network Models for voltage Contingency," International Transaction on Electrical Energy Systems, vol. 12, pp. 127-133, 2014.

[27] H. Hadj et al., "Feedforward neural network-based transient stability analysis of electric power systems," European Transaction on Electrical Power, vol. 16, pp. 577-590, 2006.

[28] G. Yang, et al., "TOSELM: Timeliness Online Sequential Extreme Learning Machine," Neurocomputing, vol. 128, no 27, pp. 119-127, 2014.

[29] X. Zhixiang et al.," modified extreme learning machine with sigmoidal activation functions," Neural Comput \& Applic, vol.22, no. 3-4, pp. 541-550, 2013.

[30] Y.Xu et al., "Real-time transient stability assessment model using extreme learning machine," IET Generation, Transmission \& Distribution, vol. 5, no 3, pp. 314-322, 2011.

[31] K. Yakup et al., "LU triangularization extreme learning machine in EEG cognitive task classification," Neural Comput \& Applic, pp. 1-10, 2017.

[32] M.Tawfek et al., "An Advanced Approach for Optimal Wind Power Generation Prediction Intervals by Using SelfAdaptive Evolutionary Extreme Learning Machine."

[33] A.Yuan et al., "Generalization ability of extreme learning machine with uniformly ergodic Markov chains Peipei," Neurocomputing, vol. 167, pp. 528-534, 2015.

[34] G. B. Huang and C. K. Siew, "Extreme learning machine with randomly assigned RBF kernels," Int. J. Inf. Technol, vol. 11, no. 1, pp. 16-24, 2005.

[35] B. P. Jiangtao et al., "Extreme learning machine for ranking: Generalization analysis and applications Hong Chena," Neural Networks, vol. 53, pp. 119-126, 2014.

[36] G. Yang, et al., "TOSELM: Timeliness Online Sequential Extreme Learning Machine," Neurocomputing, vol. 128, no 27, pp. 119-127, 2014.

[37] I. Bahiuddin, et al," Comparing the linear and logarithm normalized extreme learning machine in flow curve modeling of magnetorheological fluid," Indonesian Journal of Electrical Engineering and Computer Science, vol. 13, no 3, pp. 1065-1072, 2019.

[38] Hadi Saadat., Power System Analysis, Mc Graw -Hill Series in Electrical and computer engineering 1999.

\section{BIOGRAPHIES OF AUTHORS}

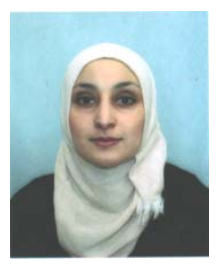

Imen LABED: was born in (1980), she received the M.S. degrees from University of Constantine 1. She is currently a Ph.D. student at a laboratory of Electric Engineering, Department Of Electrical Engineering Constantine.University of Constantine 1(Algeria).

Her research activities are currently interesting on the economic dispatch, forecasting, electrical load flow, neural networks, Extreme learning machine, and the renewable energy impact on the electrical power system. E-mail: labedimen4@gmail.com

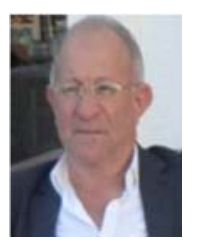

LABED Djamel is a Head of department of electrical engineering of the University Mentouri Constantine, Director of electrical engineering laboratory Constantine LGEC, Director of Research. He received an ingenerate in Electrical from University of Annaba, a Master in Electrical Research Network from the Ecole Polytechnique of Montreal, Canada, and a Ph.D. in Electrical Engineering from the University Mentouri Constantine. His research activities focus on Dispersed Generation; Analysis of different types of problem quality of electric power caused by renewable energy sources; Various techniques for optimizing the optimal power flow; Stability of groups; Power flow method for DC networks integrated into AC.

E-mail: djamel_labed@yahoo.fr

Int J Pow Elec \& Dri Syst, Vol. 10, No. 3, Sep 2019: 1244 - 1254 